\title{
PARTICIPAÇÃO NA PERSPECTIVA DE MÃES DE CRIANÇAS DESNUTRIDAS ${ }^{1}$
}

\author{
Maria de Fátima Antero Sousa Machado ${ }^{2}$ \\ Neiva Francenely Cunha Vieira ${ }^{3}$
}

Machado MFAS, Vieira NFC. Participação na perspectiva de mães de crianças desnutridas. Rev Latino-am Enfermagem 2004 janeiro-fevereiro; 12(1):76-82.

Este estudo teve como objetivo apresentar concepções e percepções de participação de mães e profissionais em Programas de Desnutrição Infantil. Examinamos em particular a participação materna, por entender ser essencial ao processo de conscientização de realidade individual e social que viabilize decisões. Este estudo analisa o processo de participação materna através da abordagem conceitual de Imogene King. O local da coleta de dados ocorreu na cidade do Crato, Ceará Brasil. Os sujeitos foram as mães e profissionais. Os procedimentos adotados foram entrevistas semi-estruturadas, e para organização e análise dos dados utilizamos a Análise de Conteúdo de Bardin. Não encontramos evidências que indique a presença de estratégias de mobilização para participação consciente entre os atores sociais do Programa de Desnutrição Infantil.

DESCRITORES: transtornos da nutrição infantil; promoção da saúde

\section{THE MOTHERS' PARTICIPATION IN THE CHILD MALNUTRITION PROGRAM}

This study aims to show mothers' and health professionals' conceptions and perceptions related to their participation in the Child Malnutrition Program. Thus, we particularly explore the mothers' participation, as a means of making them aware of the individual and social reality and their decisions about it. Our analysis of the maternal participation process is guided by Imogene King's conceptual framework. This study was conducted in Crato, Ceará State, Brazil. Study participants were mothers and professionals. We used semi-structured interviews and adopted Bardin's Content Analysis for organizing and analyzing the collected data. This study did not find evidence of strategies for the conscious participation of social actors in the child malnutrition program.

DESCRIPTORS: child nutrition disorders; health promotion

\section{PARTICIPACIÓN DESDE LA PERSPECTIVA DE LAS MADRES DE NIÑOS DESNUTRIDOS}

Este estudio tiene como objetivo presentar concepciones y percepciones de participación de madres y profesionales en Programas de Desnutrición Infantil. En ese sentido, examinamos en particular la participación materna, por entender ser esencial al proceso de concienciación de la realidad individual y social que vuelva viable las decisiones. Este estudio analiza el proceso de participación materna a través del abordaje conceptual de Imogene King. El local de la recolección de datos ocurrió en la ciudad de Crato, Ceará-Brasil. Los sujetos fueron las madres y profesionales. Los procedimientos adoptados fueron entrevistas semi-estructuradas y para organización y análisis de los datos utilizamos el Análisis de Contenido de Bardin. No encontramos evidencias que indique la presencia de estrategias de movilización para participación consciente entre los actores sociales del Programa de Desnutrición Infantil.

DESCRIPTORES: trastornos de la nutrición infantil; promoción de la salud

\footnotetext{
${ }^{1}$ Trabalho integrante da dissertação de Machado (2001); ${ }^{2}$ Enfermeira, Mestre, Professor Adjunto da Universidade Regional do Cariri - URCA, Precetora da Residência de Enfermagem em Saúde da Família da Escola de Saúde Pública do Ceará, e-mail: fatimaantero@uol.com.br; ${ }^{3}$ Enfermeira, Doutor, Professor Adjunto da Universidade Federal do Ceará, e-mail: nvieira@ufc.br
} 
INTRODUÇÃO

$\boldsymbol{O}$ crescimento acelerado do sistema capitalista, ao mesmo tempo que acumulou riquezas, ocasionou aumento das desigualdades sociais, diminuição de oferta de empregos, escoamento do dinheiro público e o acesso a bens e serviços não compatíveis com a agenda nacional. Como conseqüência social, instaura-se a existência de uma população ambígua que "coexiste" com a riqueza, ao mesmo tempo vivendo em situação de extrema pobreza e em condições, muitas vezes, sub-humanas ${ }^{(1-3)}$.

Segundo a UNICEF e OMS, estima-se que, no mundo inteiro, 190 milhões de crianças menores de cinco anos sejam cronicamente desnutridas e, ainda, que mais de $50 \%$ das mortes em crianças menores de cinco anos, nos países em desenvolvimento, tem a desnutrição como causa básica ou associada ${ }^{(4)}$.

No Brasil, a situação não parece ser diferente, pois $31 \%$ das crianças menores de cinco anos apresentam desnutrição. Nas regiões mais pobres, como o caso do Norte e Nordeste, a prevalência chega a $60 \%{ }^{(5)}$. Esses dados refletem o quadro grave da desigualdade social brasileira.

No Ceará, a mortalidade infantil tem como um dos fatores determinantes a desnutrição.

A problemática da desnutrição também permeia a cidade do Crato, localizada no sul do Estado do Ceará, com população de 96809 habitantes, sendo que 11371 são menores de 5 anos, e que $25,82 \%$ desses são desnutridos ${ }^{(6-7)}$. Até 1990 , a cidade do Crato tinha somente dois serviços especializados no atendimento à criança desnutrida, insuficientes para atender a demanda. Frente à realidade é que, em 1991, um outro programa de atendimento à criança desnutrida foi criado em uma instituição de caráter filantrópico, buscando alternativas para essa clientela, do qual tivemos a oportunidade de participar da sua criação.

Esse Programa de Desnutrição tem como objetivo recuperar crianças desnutridas leve, moderada e gravemente, buscando a participação materna como uma das estratégias para recuperar a criança.

Em estudo anterior constatamos pouca participação das mães nas ações desenvolvidas, voltadas para a recuperação de seus filhos ${ }^{(8)}$.

Essa ausência ou pouca participação materna parece resultar em um tempo necessário de recuperação mais prolongada do quadro de desnutrição de seus filhos.
Identificar os fatores que podem interferir na participação da mãe no programa poderá ser o caminho para redirecionar novas diretrizes no programa que atende uma clientela significante, e maximizar a participação da mãe no programa, para que essa recuperação seja efetiva e sem reincidivas. A percepção dos sujeitos acerca da participação foi estudada à luz da estrutura conceitual de Sistemas Abertos de Imogene King.

Participação é o caminho natural para o homem exprimir sua tendência inata de realizar, fazer coisas, afirmar-se a si mesmo e dominar a natureza e o mundo. $E$, ainda, sua prática envolve o prazer de desenvolver coisas como a interação com os outros, a auto-expressão, o desenvolvimento do pensamento reflexivo, o prazer de criar e recriar e a valorização de si pelas outras pessoas ${ }^{(9)}$. $́$ nesse sentido que a participação é entendida neste estudo, no qual os segmentos envolvidos refletem, discutem, opinam e atuam sobre uma dada realidade, no caso específico, a participação das mães no Programa de Desnutrição.

O termo "participação" é um dos mais usados hoje, em nossa sociedade. No entanto, a população tem sido pouco participativa ${ }^{(10)}$. Essa participação tem ficado no plano virtual, resultado de uma política em que as pessoas não têm consciência dos seus direitos e deveres $^{(11)}$.

Nesse sentido, se faz necessário refletir junto à comunidade, respeitando alguns princípios. "Refletir, junto com uma clientela, sobre sua realidade, partindo de alguns princípios básicos - respeito à liberdade de pensar e agir das pessoas; valorização dos processos cognitivos, da experiência pessoal no processo de atualização de si (ou processo de crescimento), da razão comunicativa, estimulando a competência comunicativa na busca do senso sobre a verdade; aplicação dos princípios da interação simbólica no diagnóstico de situações interativas e na programação de estratégias de intervenção; aplicação dos princípios da dissonância cognitiva para identificar dissonância e ajuda no retorno à consonância. Identificar a rede social de apoio natural na área e tentar estabelecer mecanismos de articulação entre duas redes - a institucional e a não institucional (ou natural)"(12).

A participação de pessoas, em uma organização, acontece quando as ações são planejadas em conjunto e o papel de cada pessoa envolvida é definido para a implementação das ações, ou seja, cada pessoa assume o compromisso e autoria do processo. Esse envolvimento 
da pessoa, no processo, é um dos indicadores que garantem o sucesso em programas de promoção da saúde ${ }^{(13)}$.

Promoção da saúde entendida como um processo de capacitação da comunidade para atuar na melhoria da qualidade de vida e saúde, incluindo maior participação dessa no controle desse processo. É direito e dever dos povos participar individual e coletivamente no planejamento e na execução de seus cuidados de saúde ${ }^{(14)}$.

Essa participação ocorre quando os recursos humanos disponíveis na comunidade são valorizados. Buscando compreender as principais dimensões dessa realidade, nosso objetivo foi analisar o processo de participação da mãe em um Programa de Desnutrição Infantil por meio da abordagem conceitual de Imogene King.

\section{MÉTODOS}

Trata-se de estudo do tipo qualitativo exploratóriodescritivo por melhor se adequar às indagações que geraram o seu objeto.

Com base nesse paradigma conceitual, exploramos, na conexão mãe - Programa de Desnutrição, os sistemas pessoal, interpessoal e social. Desse modo, cada mãe passa a ser vista dentro de um sistema pessoal membro de uma família e da comunidade, e em evolução para os sistemas interpessoais e sociais, numa interação constante e dinâmica, como elementos indutores de participação. Essa interação, como a entendemos, envolve percepção e reflexão sobre o problema, os modos de resolução e de participação dos atores sociais da organização: mães e profissionais.

A pesquisa foi desenvolvida em uma instituição filantrópica, na cidade do Crato, Ceará-Brasil.

Os sujeitos foram as mães que têm seus filhos dentro do período considerado pela instituição como prolongado para a desnutrição, ou seja, mães das crianças que estão no programa de oito meses a um ano, perfazendo o total de 11 mães. Dessas, 09 aceitaram participar do estudo e os profissionais (coordenadora e monitoras). As mães estão identificadas no estudo como: Mãe 01, Mãe 02, ... Mãe 09. Já os profissionais estão identificados no estudo como Profissional - A, B e C.

Na busca dos dados, utilizamos entrevista semiestruturada, no período de junho e julho de 2000.
Para organização e análise dos dados, utilizamos a Análise de Conteúdo de Bardin e o procedimento da análise temática.

Durante todo o processo da pesquisa, foi dada a devida atenção aos trâmites burocráticos legais determinados pela instituição e, ainda, respeitando os princípios éticos que regem a pesquisa na área da saúde.

\section{RESULTADOS E DISCUSSÃO}

As mães participantes do estudo foram 09 e estão assim identificadas: Mãe 01, Mãe 02, Mãe 03, Mãe 04, Mãe 05, Mãe 06, Mãe 07, Mãe 08 e Mãe 09. Essas mães do nosso estudo vivem em condições precárias, repercutindo no modo de vida de suas famílias e, conseqüentemente, na saúde.

Os profissionais, 02 estão no Programa de Desnutrição desde a sua criação, há 09 anos, e 01 há dois anos. Apesar da considerável diferença do tempo de serviço, não constatamos nenhum prejuízo para o estudo.

Exploração do sistema pessoal - percepção de participação de mães e profissionais

Entendendo que a participação envolve o processo de dinâmica de interação entre os atores sociais envolvidos, buscamos identificar, a partir do sistema pessoal dos mesmos, a experiência de cada ator envolvido no contexto do Programa de Desnutrição, como demonstram as colocações de mães a seguir: Participar é ir à creche quando ela chama, porque é minha obrigação (Mãe 05); Assistindo reunião e dando alimentação a ela na hora como a creche manda (Mãe 02); Eu tenho aquele sacrifício todo dia de levar eles pra merendar na creche... (Mãe 09).

Os depoimentos acima parecem indicar uma incongruência acerca da participação entre as pessoas envolvidas. Para as mães, participação é obrigação, cumprimento de ordem e sacrifício. É cumprir as obrigações estabelecidas pela creche visando a recuperação de seus filhos. Essa compreensão pode estar associada ao que Bordenave denomina de participação receptiva ${ }^{(9)}$. Esse modelo de participar pode também estar associado a uma ideologia na qual a população menos favorecida, quando beneficiada por algum tipo de serviço, entende isso como ajuda e não como um direito. Essa compreensão tende a distanciar a pessoa do processo. 
Por outro lado, os profissionais parecem compreender os elementos importantes no processo de participação como: envolvimento, compreensão, interesse e conscientização. No entanto, parecem não estar utilizando as estratégias adequadas para alcançar a participação. Os seguintes depoimentos denotam tais pensamentos: Participação das mães no programa para mim significa o envolvimento, a compreensão e a vivência delas dentro do programa (Profissional-A); Quando a mãe se interessa...(Profissional-B); ..., é elas entenderem e se conscientizarem do papel delas que participação não é só trazer, que é se envolver no trabalho (Profissional-C).

É indispensável considerar a visão de mundo e o comportamento das camadas populares para que uma participação seja efetivada ${ }^{(10)}$.

A divergência acerca da percepção de participação entre os atores envolvidos, mães e profissionais, revela, na perspectiva de King, a realidade de cada um deles ${ }^{(15)}$. Portanto, suas visões pessoais do que seja participação se encontram dissociadas e desconhecidas em ambos os lados, conseqüentemente a participação ativa, atuante e critica está prejudicada.

Exploração do sistema interpessoal - a interação, comunicação e transação entre os sujeitos

No sentido de melhor compreender os fatores que interferem na participação desse grupo em particular, procuramos examinar suas experiências e perspectivas nas formas de interação, comunicação e transação vivenciadas pelo grupo.

Interação entre mães e profissionais

O que buscamos foi capturar alguns elementos da dinâmica interna do relacionamento entre os participantes do Programa, captando as expressões por parte das mães, como ilustrado a seguir: ... eu adoro. Qualquer coisa precisando lá em casa se eu chegar lá na creche e falar com ... (profissional), ela ajuda, pronto tá tudo resolvido (Mãe 02); São tudo legal de ajudar, pedir remédio e as vez arruma até dinheiro pra gente (Mãe 02); Me disseram que ...(profissional) ajudava as crianças desnutridas, ai vim pra cá, é por isso que eu sou muito agradecida a ela, só dela ter ajudado o meu filho...(Mãe 03); Eu tenho que falar a verdade, meu relacionamento com elas é pouco... (Mãe 08).

Nas falas da Mãe 07, Mãe 02 e Mãe 03, um bom relacionamento aparece como ajuda recebida às necessidades do seu dia-a-dia. E, ainda, um forte sentimento de gratidão pela ajuda recebida.

Observamos, também, que algumas mães reconhecem dificuldades no relacionamento com os profissionais.

A interação entre mães e profissionais parece ser do tipo pedir e receber. Mais uma vez evidenciamos que as condições sociais e de vida dessas mães tendem a direcionar o seu relacionamento no patamar de suas necessidades básicas.

Os profissionais também foram questionados acerca do relacionamento entre os participantes do Programa, conforme colocado nos depoimentos: Nós temos uma relação muito aberta; existe essa confiança das mães comigo até porque eu cheguei bem antes de existir esses programas aqui. O diálogo é fácil... (Profissional-A); No início, meu contato era diretamente com as mães, desde a convocação das mães, a elaboração das reuniões, hoje presto assessoria ao programa (Profissional-B); No início, logo que eu entrei, eu sentia dificuldades no relacionamento... (Profissional-C).

Os profissionais vêem a dinâmica de relacionamento pela presença de elementos como: confiança, diálogo, convocação e execução de reuniões. Embora aceitemos serem importantes esses elementos, o confronto das falas não revela traços efetivos de uma comunicação, interação e transação no grupo, condizente com o tipo de participação que defendemos: dialógica, consciente e de responsabilidades compartilhadas nas tomadas de decisões e ações.

As condições nas quais acontece 0 relacionamento entre mães e profissionais é num modelo clientelista $\rightarrow$ assistencialista.

A comunicação entre mães e profissionais

Um outro ponto abordado no estudo foi o processo de comunicação entre as mães e os profissionais, conforme demonstram as colocações dos atores envolvidos: $E u$ sempre fico só escutando, não pergunto; eu tenho vergonha de tá perguntando, acho melhor ficar calada escutando e fazer o que eles manda a gente fazer (Mãe 06); Eu nunca vou lá na creche falar com ...(profissional), eu nunca fiz isso (Mãe 08); Muitas vezes eu fico com vontade de dá alguma opinião, aí fico assim com vergonha, com medo, então fico calada (Mãe 01); A participação delas nas reuniões não era tão grande; elas ficavam mais de ouvir ou de dizer sim ou não. Hoje elas já têm condição de falar, de mostrar como são 
as necessidades (Profissional-A); Sempre um animador comunitário sonda o que as famílias querem ouvir e aí a gente sempre procura atender... (Profissional-C).

Para as mães, a vergonha e o medo foram tidos como fatores impeditivos para não falar, não perguntar e, talvez, não gostar de falar.

Há ainda mães que nunca procuraram a equipe do Programa, como afirma a Mãe 08.

$\mathrm{Na}$ visão dos profissionais, embora acenando algumas mudanças positivas, confirmam-se as dificuldades das mães. Algumas tentativas ilustram o esforço da equipe como, por exemplo, a articulação dos animadores comunitários junto às famílias.

A comunicação é um veículo importante em um relacionamento interpessoal, quando não acontece surgem dificuldades impedindo que a interação aconteça, que resultaria no alcance de metas, nesse caso, em particular, a participação das mães no Programa.

A comunicação promove a interação entre as pessoas $^{(15)}$. Assim sendo, acreditamos que a dificuldade na comunicação, constatada pelas falas das mães e dos profissionais, é um dos fatores impeditivos à participação das mães no Programa.

Pelos dados apresentados, percebemos que a comunicação é unidirecional no sentido profissionais $\rightarrow$ clientela.

\section{A transação no processo de participação}

A dinâmica interna que regula ou direciona essa transação foi identificada através de indicadores obtidos nas falas dos sujeitos, as quais enfatizaram o modo de participação das mães no Programa e os Fatores que interferem na participação das mães, segundo os profissionais: Eu já participo de todas reunião, todo chamado eu vou e fico prestando atenção (Mãe 06); Mudando a alimentação dela, agora faço uma sopa especial para ela, eu acho que assim estou ajudando (Mãe 08); Eu faço o mingau com o poinho que trago de lá... (Mãe 09); Crianças que são criadas por avó, tia e por outras pessoas, mães alcoólatras, mães que trabalham fora e que não acompanham a criança, aquelas que não compreenderam isso como importante... (Profissional-A); Eu acho que seja a conscientização delas assim em relação aos programas que a creche oferece, 0 número de filhos, o próprio comodismo delas e as questões sociais dos pais como, por exemplo, o desemprego (Profissional-C); Não vejo a escolaridade como algo que interfere... (Profissional-A); $A$ escolaridade não interfere na participação das mães... (ProfissionalC).
Pelo lado materno, a sua forma de participação, é identificada pelos indicadores, como: freqüência, atenção, aprendendo a cuidar da criança.

$\mathrm{Na}$ realidade, elas cumprem as metas que são ditadas pelos profissionais, o que caracteriza uma tentativa de participação.

À luz da estrutura conceitual de King, a transação se dá a partir do cumprimento de metas. Segundo as falas, as metas são cumpridas, mas centradas nas da organização, qual seja - a recuperação da criança desnutrida. Embora a mãe também assim o deseje, essa meta encontra-se restrita aos determinantes biológicos, o que não garante a sustentabilidade da recuperação.

Por sua vez, a equipe indicou alguns elementos que impedem maior participação das mães no Programa, como: vínculo criança-família, auto-estima, nãoconscientização, número de filhos, comodismo e desemprego.

É importante indicar que, na visão das mães, sua participação acontece, enquanto os profissionais limitaram-se a apresentar as dificuldades da participação materna. Esse padrão distinto de respostas pode indicar que há dissonância na transação no processo.

A compreensão do sistema social pelas mães e profissionais por meio da organização, autoridade, poder e tomada de decisão

No sistema social, procuramos desvelar experiências e percepções das mães e dos profissionais, conhecendo qual o papel assumido por eles através da organização, autoridade, poder e tomada de decisão. Essas categorias estão presentes ou compõem o sistema social no contexto das pessoas. As colocações dos participantes revelam o espaço organizacional na perspectiva dos profissionais e das mães: Eu só falto às reunião porque saio de casa às cinco da manhã e só chego às seis da noite (Mãe 07); A creche para mim é uma família... (Mãe 02); Eu não tenho tempo disponível para meus filhos, mas o tempo que eu posso dou banho, gosto de pentear e gosto de ver eles limpinhos (Mãe 08); Para as atividades das mães existe um planejamento onde através de dinâmicas e visitas elas vão avaliando e vendo o que é que realmente elas estão precisando em termos de comunidade (Profissional-A); É feito o planejamento mensal, onde toda a equipe da creche se reúne e a gente vê de acordo com o plano anual quais são as ações que a gente pode trabalhar naquele mês (ProfissionalB); A gente senta, planeja antes de repassar pra família... 
(Profissional-C); O planejamento é restrito à equipe... (ProfissionalC).

Observamos que essas mães, quando contam com algum tipo de ajuda de organizações existentes no seu bairro, a ela se agarram e percebem a instituição como extensão da família, por solucionar alguns dos problemas do seu cotidiano.

Nas falas da Mãe 07 e Mãe 08, percebemos a imposição da abstinência da participação no Programa pela sobrevivência, quando afirmam não comparecerem às reuniões e nem cuidarem dos filhos, por não disporem de tempo.

Constatamos pelas falas dos profissionais, uma exclusão das mães, no modo como a organização planeja suas atividades. As decisões são tomadas pela equipe e, posteriormente, são repassadas às mães, o que caracteriza ações verticalizadas, que anulam um prérequisito importante para a participação: o acesso de todos os membros da organização para a tomada das decisões.

Entre os parâmetros estabelecidos para que uma organização aja em benefício dos seus membros, é a abertura para uma interação no grupo ${ }^{(15)}$. É importante que todos conheçam a filosofia, as metas, funções, recursos e quem toma decisões em todos os níveis da organização ${ }^{(13)}$.

Embora as mães reconheçam a creche como uma organização importante, não participam das decisões nas quais elas e seus filhos estão envolvidos, o que caracteriza exclusão social das mães no processo.

Autoridade, poder e tomada de decisão no processo de participação

Optamos por apresentar as categorias autoridade, poder e tomada de decisão juntos, por entender que existe íntima relação entre essas categorias. As falas, a seguir, evidenciam, com clareza, essa relação:

Autoridade: Tudo que eles mandam fazer lá na creche eu faço direitinho... (Mãe 06); Quando manda me chamar eu sempre venho... (Mãe 03); Eu atendo todos os chamados... (Mãe 08); Geralmente a gente senta diante do levantamento de crianças desnutridas e decidimos o que vamos fazer (Profissional-C).

Poder: A creche ajuda nesse negócio aí de desnutrição... (Mãe 07); Sou satisfeita por ela ter ajudado meu filho desnutrido... (Mãe 04); ... a creche é muito importante porque se a pessoa precisa ela ajuda... (Mãe 01); $A$ instituição motiva, a instituição ajuda, mas a mãe mesmo é que tem que ver que ela é que tem que compreender isso e que as coisas só se modificam a partir da gente mesmo (Profissional-A); Nós convidamos as mães para que elas dêem a contribuição delas... (Profissional-C).

Tomada de decisões: Eu nunca cheguei pra falar... (Profissional) vamos mudar isso aqui, nunca dei opinião....(Mãe 08); Nós estamos fazendo um trabalho, a oficina da conquista, para valorizar, estimular e elas descobrirem o quanto são importantes (Profissional-A/Profissional-C); Agora nós montamos o jantar da recuperação, aí elas trazem as crianças... (Profissional-C).

Percebemos, pelas falas destacadas, certa autoridade dos profissionais sobre as mães. Essa autoridade é manifestada pela obediência das mães às decisões e chamados da creche.

Essa autoridade profissional é reconhecida e acatada pelas mães diante da capacidade e poder da organização de solucionar seus problemas. Elas percebem um deslocamento de forças: por um lado, elas estão diante das condições sociais de vida, impotentes; e do outro, a instituição e a equipe decidem por elas.

A autoridade expressa relação de subordinação de uma pessoa a outra. Poder mantém a relação de autoridade ou influencia o outro. A forma como se relacionam as categorias poder e autoridade, em um grupo, refletirá nos processos de participação e na decisão de seus membros ${ }^{(15)}$.

Nesse contexto, a autoridade é do tipo dominador x dominado, o poder é consentido e as decisões são de forma central e vertical.

\section{CONSIDERAÇÕES FINAIS}

Os dados apresentados parecem indicar que uma participação crítica e transformadora ainda está longe de ser alcançada, apesar dos esforços empreendidos. As bases do relacionamento entre as mães do Programa e profissionais ainda estão enraizadas num determinante biológico, e em ações verticais que contribuem para a exclusão social.

O nosso estudo indica dissociação de participação dentro do sistema pessoal dos sujeitos. Eles emitiram sua percepção de participação a partir de experiência pessoal.

No sistema interpessoal dos sujeitos, a interação, comunicação e transação não acontecem na medida em que compreendemos a participação dialógica, consciente 
e de responsabilidades compartilhadas. A interação é do tipo clientelismo/assistencialismo, a comunicação é unidirecional e, na transação, os sujeitos divergem na compreensão de como se dá o processo.

No sistema social, vivenciado pelos sujeitos, permeiam indicadores que impedem a participação. As mães estão excluídas do planejamento das atividades da organização, há relação de subordinação da mãe em relação aos profissionais, a instituição detém um poder consentido, no processo, e as decisões são tomadas de forma central e vertical.

Evidenciamos que o Programa de Desnutrição atende a uma necessidade da comunidade, que é recuperar crianças desnutridas. No entanto, a garantia da sustentabilidade dessa promoção da saúde está prejudicada pela ausência de instrumentos que viabilizem a participação das mães nas ações do Programa.

Reconhecer as pessoas da comunidade como o principal recurso para alcançar o sucesso nas ações de promoção da saúde é o caminho que deveremos percorrer.

\section{REFERÊNCIAS BIBLIOGRÁFICAS}

1. Harnecker M, Uribe G. Capitalismo e socialismo. São Paulo (SP): Global; 1980.

2. Jaguaribe H, Valle e Silva N, Abreu MP, Ávila FB, Fritsch W. Brasil: reforma ou caos. $2^{\underline{a}}$ ed. Rio de Janeiro(RJ): Paz e Terra; 1989.

3. Valente FLS. Fome e desnutrição: determinantes sociais. São Paulo (SP): Cortez; 1989.

4. Nobrega FJ, Campos ALR. Distúrbios nutricionais e fraco vinculo mãe-filho. Rio de Janeiro (RJ): Revinter; 1996.

5. Barros, DIM, Potenza ANS, Sardinha FA, Silveira SF, Fisberg $\mathrm{M}$, Ancona Lopez F, et al. Comparação do conhecimento sobre nutrição entre mães de crianças desnutridas e eutróficas. Rev Paul Pediatr 1996;14(3):107-12.

6. IBGE. Censo demográfico do Brasil. Rio de Janeiro: IBGE;1996.

7. Benicio MHD'A, Monteiro CA. Desnutrição infantil nos municípios brasileiros: risco de ocorrência. Brasília (DF): UNICEF; 1997.

8. Machado MFAS. Avaliando um programa de desnutrição. [monografia]. Juazeiro do Norte: Universidade de Ribeirão Preto - UNAERP; 1992.

9. Bordenave JED. O que é participação. $2^{\underline{a}}$ ed. São Paulo (SP): Brasiliense; 1985.

10. Valla VV. Participação popular e saúde: a questão da capacitação técnica no Brasil. In: Valla VV, Stotz EN, organizadores. Participação popular, educação e saúde: teoria e prática. Rio de Janeiro (RJ): Relume-Dumará; 1993. p.56-86.

11. Almeida VL. Saúde e cidadania: a experiência de IcapuíCE. Fortaleza (CE): Fundação Cearense de Pesquisa e Cultura; 1999.

12. Varela ZMV. Construindo no cotidiano de sobrevivência da família - uma opção em enfermagem comunitária. Fam Saúde Desenv 1999;1(1/2):75-86.

13. Nutbean D, Harris E. Theory in a nutshell: a practitioner's guide to commonly used theories and models in health promotion. Austrália: University of Sydney; 1998.

14. Ministério da Saúde (BR). Diretrizes para o tratamento da criança severamente desnutrida à nível hospitalar no Brasil. Brasília (DF): Ministério da Saúde; 1999.

15. King IM. A theory for nursing: systems, concepts, process. New York: Wiley Medical Publicantions; 1981. 